\title{
Professional Development for Institutional Research
}

\author{
Herman Visser and Glen Barnes
}

\section{Introduction}

Throughout the history of higher education, some kind of evidence has been required to validate decisions or make them credible. Over time, the provision of evidence to support decision making in higher education institutions has fallen to institutional researchers as their roles and functions have evolved. The roles of institutional research offices and of institutional researchers differ between institutions. According to Calderon \& Webber (2015:1), "Many of the functions attributed to IR have evolved in parallel to the evolution and transformation of institutions of higher learning across centuries. Every turn of the decision-making process at any institution, has required some kind of evidence or an argument that brings validity or legitimacy for any proposal under consideration".

In this chapter, we consider the skills and competencies needed by institutional researchers to enable them to conduct effective and cutting-edge institutional research that will meet the requirements for institutional intelligence, in particular, technical/analytical intelligence, issues intelligence and contextual intelligence, as described by Terenzini (1993 \& 2013). We also examine the ways in which these roles and functions can be developed and enhanced. In our discussion, we will focus on (1) the challenges related to the professional development of institutional researchers, (2) the nature of institutional research and the requirements for effective institutional research, (3) the role and contribution of the professional development activities of the Southern African Association for Institutional Research (SAAIR), (4) the impact of changes in the higher education and technical environments on the skills and competencies required from institutional researchers to support these and (5) how the required skills can best be developed by a volunteer professional association such as the SAAIR. In this chapter, we use the notions of "professional development" and "capacity development" interchangeably.

\section{Professional development in the context of institutional research}

Reflecting on the requirements for the professional development of institutional researchers, Chase \& Tetlow (1979:23) point out that the broad scope of institutional research and the diverse functional, organisational and human factors related to it make it a challenging undertaking, though any attempt at professional development is better than taking no action. 
Dressel (1979) argues that the experts who are offering professional development opportunities to institutional researchers should recognise that the conceptions of institutional research vary between individuals, within and between institutions, and over time, and that these variables should be taken into consideration when opportunities for capacity development are designed and presented. Development programmes for institutional researchers should include opportunities for professional self-reflection and should consider their capacity in their roles in higher education institutions, the higher education system and scholarly or disciplinary associations.

Capacity development can take various forms which complement each other, but may overlap. These include formal qualifications/programmes, short learning programmes, training courses offered in-house or by external providers, on the job training opportunities (including mentoring), and professional development initiatives offered by subject associations.

Professional development opportunities for institutional researchers are informed and guided by the ever-changing range of issues facing them. Professional development should be a balance between theoretical knowledge, experience and critical thinking.

Slowy and Kozina (2013:56) indicate that professional development opportunities should be needs based. Institutional research professionals should have opportunities to keep themselves abreast of new developments in their field and to enhance their knowledge and skills on an ongoing basis. They need to understand the gaps and barriers in their practice and must be able to identify priority areas for their professional development.

\section{The nature of institutional research and the requirements for effective institutional research}

In order to determine the development needs of institutional researchers, it is important to understand the nature of institutional research and the requirements for effective institutional research.

Terenzini (1993) based his concept of the nature of, and requirements for, effective institutional research on the work of Fincher (1979:189-192), further informed by his own IR experience over many years. Terenzini came to think of IR as requiring multiple forms and sources of intelligence, each different from the other, and each a necessary though not in itself sufficient part of an integrated hierarchy. He developed a three-tiered hierarchy of the organisational intelligence required to be effective in institutional research. He describes organisational intelligence as consisting of three different but equally important and interdependent forms and sources of personal and professional competence, institutional understanding and experience and knowledge necessary to be an effective IR professional. He distinguishes between Technical/Analytical intelligence (Tier 1), Issues intelligence (Tier 2) and Contextual intelligence (Tier 3). Although these forms of intelligence can be conceptualised as a three-tier hierarchy because the skills required for each tier builds on the preceding tiers, the three tiers are equally important and independent. The representation in Figure 1 is based on and provides an overview of Terenzini's three tiers of organisational intelligence (Terenzini 1993 and 2013). 




Figure 1: Diagrammatic representation of Terenzini's three tiers of organisational intelligence

According to Terenzini (1993:23-24), Technical/Analytical intelligence is the foundational form of intelligence required by institutional researchers. This type of intelligence is made up of technical and analytical skills. Technical skills include knowledge and information about data structures, data elements, operational definitions and counting rules, while the analytical component involves skills to conduct social science research.

Issues intelligence (Terenzini 1993:24-25) includes both substantive and procedural components. The procedural component relates to the way the institution functions and how decisions are made. It also includes the political character and informal power structures of the institution. The substantive component relates to the major problems facing an institution on which the technical and analytical intelligence is applied. Leimer \& Terkla (2009:44-45) also investigated the nature of the attributes and skills needed by institutional researchers that would enable them to conduct cutting-edge institutional research. Leimer \& Terkla (2009:53) empasize the importance of social intelligence, a component of issues intelligence in Terenzini's framework of institutional intelligence. Excellent people skills are required for institutional researchers; they must be able to understand and navigate complex social situations.

According to Terenzini's framework (Terenzini 1993:25), contextual intelligence involves an understanding of the culture and history of higher education in general, and an understanding of the particular campus or environment where the institutional researcher works. Contextual intelligence reflects organisational intelligence, experience and knowledge and according to Terenzini: 
It makes possible the prudent, intelligent, and illuminating application of technical and methodological intelligence to locally meaningful versions of general issues. It represents both content and methodologies tailored for a specific institutional setting where real people are preparing to make real decisions. It is the form of intelligence that earns institutional research and researchers legitimacy, trust, and respect. (Terenzini 1993:7).

Institutional researchers perform activities that require a blend of skills across the three organisational intelligence tiers. In some instances, issues intelligence or contextual intelligence can be provided by specific team members while less experienced team members may only perform activities related to technical/analytical intelligence.

Recently Terenzini revisited the hierarchy of organisational intelligence (Terenzini 2013) when questions were raised about its relevance after two decades. He concluded that all three tiers retained their relevance, but that they needed to be redefined to some degree to reflect current realities. Technical/Analytical intelligence is impacted on heavily by the dramatic changes in information technology in the intervening time. Terenzini (2013:139140) highlights the danger for institutional researchers of potential preoccupation with technology and the decline in response rates of surveys because of survey fatigue. With respect to Issues intelligence, Terenzini points to the need for greater awareness of, and responsiveness to, the changing educational and political scenes, the need for more extensive familiarity with the research literature and more subtle, intuitive and insightful political skills that are now required of institutional researchers. In terms of contextual intelligence, he highlights the dramatic changes to the external environment of institutions as having a major impact on the researcher in providing an effective context for research.

Drawing on this conceptual framework, issues of skills, expertise, experience and development opportunities must be considered in order to understand the challenges faced by the IR practitioner in the changing higher education landscape.

A brief summary of relevant surveys and of research conducted in the USA on IR follows.

In an attempt to provide empirical validation of Terenzini's framework, Knight, Moore \& Coperthwaite (1997:422) conducted a national survey of the membership of the Association for Institutional Research (AIR) against which they matched the three forms of intelligence with institutional research practice in the United States of America. Surveys were mailed to 1234 persons of whom 35 indicated that it was not applicable to them, resulting in 1199 valid surveys. Of these, 695 were returned, giving a response rate of $58 \%$. The respondents had been in the profession for an average of 7 years, with duration of employment ranging between 1 and 35 years. 57\% of the respondents held appointments at the level of Director, while $10 \%$ were at the level of Assistant/Associate Director.

Respondents were requested to classify the nature of their work in terms of the three tiers of intelligence in Terenzini's hierarchy and to indicate to what extent their skills clusters conformed to Terenzini's three tiers of intelligence. Their survey yielded the following results ranging from the lowest reported proportion to the highest reported proportion: 
Technical/Analytical intelligence (70-81\%), Issues intelligence (53-79\%), Contextual intelligence (28-66\%).

Gagliardi \& Welman (2015) developed surveys of systems and campus IR offices on behalf of the National Association of System Heads (NASH) and in collaboration with the AIR. On the basis of these surveys, they conducted interviews with institutional research professionals and users of institutional research. The results indicate that IR is a function dominated by data collection and report writing, and that the analytical and communication functions are less well developed and largely siloed. Holistic analytics about overall performance is often neglected.

Using responses from the 2012 AIR Survey of work tasks across the USA and Canada, Dawson, Rogers \& Webber (2015:1-18) attempted to summarise and align the reported work task of institutional research practitioners with Terenzini's tiers of organisational intelligence. In the process, they condensed the 1450 reported tasks to 750 tasks and mapped these against the three tiers of organisational intelligence. Dawson et al. found that the majority of tasks could be linked to Tier 1, Technical/Analytical Intelligence. They proposed that streamlining some of these Tier 1 tasks might allow institutional researchers to work at higher levels of institutional intelligence.

Volkwein, Liu \& Woodell (2012:22-39) conducted a survey of more than a thousand IR offices at higher education institutions in the USA, and, on the basis of the responses, they developed a classification of the organisational characteristics of institutional research offices. They proposed the following "institutional research ecology", consisting of four categories (Volkwein et al. 2012: 27-28):

Firstly, craft structure (typically 1 and 2 person offices): These offices are highly burdened by mandated routine reporting and a modest amount of calculation on data. They are typically found in institutions with enrolments below 5000 or where IR is fragmented.

Secondly, small adhocracies (2 to 3 person offices): These offices are typically at an intermediate stage of development with a flat hierarchy, simple division of labour and the beginning of specialisation. They typically take on applied research projects, modest policy analysis and routine reporting. This category makes up more than a third of all IR offices in the USA.

Thirdly, professional bureaucracies (at least 4, but typically more persons): These are typically found in larger institutions with a more formal arrangement, modest bureaucratic hierarchical structure and division of labour into specialities. They typically also conduct the most sophisticated research projects.

Fourthly, elaborate profusion: These offices are most common at research universities, especially private research universities. They are decentralised, but loosely coordinated and normally have teams of researchers.

It is interesting to note the distribution of these four categories of IR offices across the Higher Education Institutions that participated in the study: 




Figure 2: IR office size, FTE professionals and IR office category

Source: Adapted from Volkwein et al. 2012

The size and scope of the responsibilities of South African institutional research offices are discussed by Muller, Langa \& Dlamini in Chapter 4. They found that on average the South African offices have six staff members, compared to three in the USA. This is probably because of the large number of community colleges in the USA that often have small offices (often staffed by one person or even only a part-time staff member). Most Southern African higher education institutions have more than five thousand students which probably explains why the majority of South African IR offices offices are classified by Muller et al. as Professional Bureacracies.

Apart from these examples, institutional researchers and their professional development are also affected by the analytical maturity of the institutional research office and the analytical maturity of their institution. This includes the shift from historical reporting to business intelligence and business analytics. Although not simply a linear progression, analytical maturity involves descriptive analysis, diagnostic analysis, predictive analysis and prescriptive analysis, typically in a combination appropriate to support the institution's issues. In terms of data sources, analytical maturity involves the movement from a single or limited number of structured data sources to multiple data sources, including some that are not necessarily structured. It implies the integration not only of internal data, but also of external data and of the use of analysis on Big Data.

\section{Staff development practices and needs of South African IR Offices}

Breen, Jaganyi, Van Wilgen \& Van Wyk (2004:429) refer to a World Bank study that highlighted the need to build human and institutional capacity in virtually all sectors and 
countries in Sub-Saharan Africa, including higher education. That such a need exists in higher education is confirmed by the interest in the professional development opportunities provided by the SAAIR, and the increasing number of colleagues attending these events.

The survey by Muller et al. of IR offices in South Africa included two questions on staff development which will be discussed here. The first question on staff development focussed on current staff development practices, while the second was intended to probe the need for staff development opportunities. The majority of the respondents ( 9 of the 12), indicated that they currently use conferences and workshops for the professional development of their staff. Only one institution, with a small IR office, did not list any current staff development opportunities. A number of the respondents referred specifically to the ongoing staff development opportunities offered by the SAAIR, including the SAAIR HEMIS Workshops and the opportunities for SAAIR members to participate in the online courses of the Data and Decisions Academy of the AIR. Other staff development opportunities mentioned by the respondents included institutional support for their staff members to study towards formal qualifications (for example Postgraduate Diplomas) or to do short courses on a range of themes (including the use of databases, business intelligence and analysis tools, research ethics, higher education policy studies, and leadership and personal skills development on topics such as time management or conflict resolution).

In addition to the these opportunities for staff development the respondents indicated a need for staff development opportunities on topics such as understanding different operational systems and their integration, business intelligence, data analytics, scenario planning and research methodology. They also felt the need for formal training in the use of statistical software packages. One respondent mentioned a need for more travel opportunities for IR for staff on exchange visits to other institutions in South Africa and internationally to learn from best practices elswhere. One respondent highlighted the lack of time for their staff members to attend training opportunities, while another respondent emphasised the need for online courses to keep costs down and to enable their staff to participate in a more flexible manner in such development opportunities.

\section{Professional development opportunities for institutional researchers}

As we have indicated, capacity development can take various forms which complement each other, but may overlap. These include formal qualifications/programmes, short learning programmes, training courses offered in-house or by external providers, on the job training opportunities (including mentoring), and professional development initiatives offered by subject associations.

We now turn to a discussion of two of the staff development formats indicated earlier, namely formal qualifications and in-service training, and professional development activities under the auspices of a professional association. We focus on the professional development activities of the SAAIR.

In the USA, a number of Graduate Certificates, Masters and Doctoral qualifications that prepare institutional researchers are available, some in collaboration with the AIR. 
Despite concerted efforts of the SAAIR to introduce a dedicated Postgraduate Diploma in Institutional Research, this did not materialise. One institution was prepared to expand their Postgraduate Diploma in Education Management to include an Institutional Research option through distance education, but required the SAAIR to provide substantial inputs for the development and delivery of some of the modules, which was not possible at the time. It is noteworthy that, thus far, no professional association related to the professional support services in higher education in Southern Africa has succeeded in introducing a formal qualification, although many of those associations have the ambition to do so, for example, the South African Research and Innovation Management Association (SARIMA 2013:126). However, as indicated above, formal qualifications are not in themselves sufficient to prepare institutional researchers for the skills required to perform their duties. Romeu (2011:1) came to the same conclusion with regard to training in statistics for engineers. He identified a number of role players needed to compensate for this. Some of the important role players he identified are professional organisations and associations.

We do not discuss in-service training in this chapter since these initiatives are varied and largely based on the IR capacity and maturity of those IR offices that offer such training opportunities to their staff. Smaller and less mature offices typically do not have the capacity to conduct in-service training and often need to outsource training and/or make use of professional development initiatives offered by subject associations.

As can be expected from a large and mature subject association such as the Association for Institutional Research (AIR) in the USA - which was established more than 50 years ago - the association offers a wide range of opportunities for professional development to its members. Following the example of this well-established association in the USA, the SAAIR also considers staff development as part of its core mission. During the first ten years of its existence (1994-2004), the SAAIR focussed primarily on the Annual Conference (earlier called the Annual Forum) as the opportunity for interactions between members and for their professional development. Since 2004, however, the SAAIR has developed and offered custom-made training opportunities in four areas: technical training in the Higher Education Management Information System (HEMIS), technical training in data and statistics, training for quality assurance officers and technical training in learner analytics. We now provide an overview of these four types of training opportunities.

The first opportunity for professional development offered by the SAAIR was a HEMIS Institute, hosted at the University of South Africa in May 2004. Following the example of the AIR, this development opportunity was called an "institute". The HEMIS Institute is a training opportunity focussed on the Higher Education Management Information System (HEMIS), the unit record-reporting system introduced by the South African Department of Education (DoE). The introduction of the new system in 2004 posed various challenges to institutions and the SAAIR responded to this need. Experienced members of the SAAIR presented a HEMIS Institute. The SAAIR invited the Department of Education from the outset to participate in the HEMIS Institutes. In 2004 the Department sent their Director of HEMIS as an observer, and from 2005 senior officials of the DoE, in 2009 reconfigured as the Department of Higher Education and Training (DHET), have been co-presenters at all the SAAIR HEMIS Institutes. This cooperation led to the official acknowledgement of the 
SAAIR by the DHET as a key stakeholder. The SAAIR was invited to serve on the DHET's Information Standards Committee (Republic of South Africa 2013:21) and on the Higher Education Tertiary Management Information System (HETMIS) Steering Committee, which oversees the broader management of information systems for the whole post-secondary education and training system. Subsequently, senior officials of the Council for Higher Education (CHE) have also participated as co-presenters where appropriate. Responding to the feedback of delegates, the programme of the HEMIS Institute was continuously adapted to address new training needs of SAAIR members. Since 2006, the programme was designed in such a manner that it provides custom-made learning opportunities for experienced and less experienced colleagues. This balance has changed slowly over time and, since 2010, the HEMIS Institute has taken the format of a forum for the discussion of advanced HEMIS and related matters. Over time the participants in the SAAIR HEMIS Institutes have broadened to include IR staff from universities in other countries of the Southern African Development Community (SADC) and delegates from private institutions and Technical and Vocational Education and Training (TVET) colleges. Neither the private institutions nor the TVET colleges report on HEMIS, but the long-term plan of the DHET is that the external reporting of both these institution types will eventually be included in HETMIS. With the change in focus of the HEMIS Institutes to a more experienced target audience, new and inexperienced members of SAAIR expressed the need for a HEMIS training opportunity at an introductory level. In 2011 the first SAAIR National HEMIS Foundations Workshop was offered and has since become a regular feature on the SAAIR calendar, presented on the day before the HEMIS Institute. The Foundations Workshop has proved so popular that it has been repeated on a regional basis which has enhanced the discussions from a regional perspective. Given the central role of HEMIS in the operations and management of South African universities, staff members in other units, such as quality assurance officers, planners and administrative staff responsible for student registration, have begun to attend the HEMIS Workshops. Over time, participation in the SAAIR's HEMIS training opportunities has expanded to include Deans and Chairs of Academic Departments. In 2015, the HEMIS Workshop was the first SAAIR professional development event with an enrolment of more than 100 delegates.

In 2004, the SAAIR offered the first Institutional Research Institute at the (then) Cape Peninsula Technikon as a joint venture with the AIR, which was presented by four experienced trainers from the AIR. The training took the form of a course over two weeks with the focus on data and statistics (see Chapter 2 for more detail). From 2005, experienced SAAIR members annually offered an IR Institute, usually over a period of two and a half days. Initially, two separate workshops in 2005 were integrated and consolidated into one from 2006, based on delegate feedback. Responding to the need for IR training at an introductory level and aimed at newly appointed and inexperienced staff, the first SAAIR Foundations of Institutional Research Institute was offered in 2015. In 2011, a workshop on Institutional Research was also presented in Botswana by two experienced institutional researchers from South Africa as part of a joint Quality Assurance/Institutional Research workshop in Gaborone in collaboration with Botswana's Tertiary Education Council (see Chapter 2 for more detail). 
The SAAIR offered its first Quality Assurance Institute in 2010 at the University of South Africa, which has since become a regular event on the SAAIR agenda. These institutes are offered by experienced SAAIR members, though, as a rule, senior officials from the DHET and the Higher Education Quality Committee (HEQC) of the Council on Higher Education $(\mathrm{CHE})$ are invited to present one or more sessions. The programme for the QA Institutes is determined in consultation with national bodies such as the HEQC, but also in response to the needs of QA practitioners working in higher education institutions. In 2011, a workshop on Quality Assurance was presented in Botswana by two experienced institutional researchers from South Africa.

In 2014 and 2015, a joint pre-conference workshop on learning analytics was offered jointly by the SAAIR and the South African Higher Education Learning Analytics (SAHELA) the day before the SAAIR Conference. In 2015, the SAAIR offered the first Learning Analytics Institute over one day at the University of Pretoria, facilitated by an experienced international expert from the AIR. The 2016 Institute was offered over two days and facilitated by three experienced South African institutional researchers. Although learning analytics is still a new field, also internationally, these events were all well attended (see Chapter 12).

An analysis of the feedback of participants in the SAAIR training opportunities discussed above indicates that the organisation of events was rated higher than the delivery of programmes (Barnes 2012). Although this is a compliment to the SAAIR and the various local organisers, this feedback is a serious concern. The relevance and content of the Institutes were also rated higher than the delivery of programmes.

In addition to the face to face training opportunities offered by the SAAIR, the association has entered into an agreement with the AIR that SAAIR members can enrol for on-line courses in IR which have been developed and offered by the Data and Decisions Academy of the AIR. The first cohort of SAAIR members enrolled in 2010 and graduated in 2011. The advantage of this format is that IR staff members can do the courses in a flexible manner and that the training has an international flavour. On the other hand, these online training opportunities do not replace the face-to-face workshops.

\section{The impact of changes in the higher education and technical environments on the skills development of IR practitioners}

Based on current trends and developments, Calderon \& Mathies (2013:77) identified the continued massification of Higher Education, increased links of HEls to economic development and a continued evolution of HEls to more complex organisations as three important environmental factors to consider. In addition to these aspects, another important factor will be the continued demand on HEls for improved efficiency. This pressure to produce more with less will mainly be driven by continued demands for improvements in student success in spite of lower public funding in real terms, but possibly even in absolute terms. External accountability is likely to increase despite the decrease in government contributions to HEls. These factors, and the increased use of technology in teaching and learning processes and in student support, have significantly impacted on institutional research and institutional researchers. This trend is expected to continue at an increasing 
rate in the foreseeable future. The pressure on higher education institutions to accommodate more students, to improve student success and institutional efficiency also continues to increase. The discussion on Terenzini's organizational intelligence framework above, and in particular the 2013 article, also highlights some of these aspects. Terenzini also pointed to the impact of the changing technical environment on Technical/Analytical intelligence.

In what follows, we argue that the changes in the technical environment will impact to some degree on all three tiers of organisational intelligence.

Rapid and significant changes in recent times in areas such as business intelligence, big data and learning analytics inevitably affect the work of IR practitioners, and we foresee that it will be essential for institutional researchers to become more involved in these aspects. This will pose new requirements and opportunities for appropriate staff development. In this regard, the professional development opportunities in learning analytics should be encouraged and even extended to other applicable areas affecting the work of IR practitioners.

Institutional researchers are increasingly seen as change agents, and they will be expected to play an important role in establishing communities of practice to respond appropriately to the new environment in information practices (Leimer \& Terkla 2009; Swing 2009).

Chen, Chiang \& Storey (2012:1165) maintain that "[b]usiness intelligence and analytics $(B I \& A)$ and the related field of big data analytics have become increasingly important in both the academic and the business communities over the past two decades." They refer to two important studies in this regard. The first study was the 2011 IBM Tech Trends Report based on a survey of 4000 information technology professionals from 93 countries and 25 industries which identified business analytics as one of four key technology trends in the 2010s. The second study, by the McKinsey Global Institute, predicted that by 2018 the United States alone will face a shortage of between 140000 and 190000 people with deep analytical skills and a shortfall of 1,5 million data proficient managers with the capacity to analyse big data to make effective decisions. Both of these findings are likely to have significant implications for institutional researchers and their role in higher education institutions of the future. Chen et al. (2012:1166-1169) distinguish three phases in the evolution of business and analytics and identify key characteristics for each of the three phases. In the table below, they summarise the key characteristics of the different BI\&A phases in relation to the Gartner BI Platforms Core Capabilities and the Gartner Hype Cycle. 
Table 1: Business Intelligence evolution - key characteristics and capabilities

\begin{tabular}{|c|c|c|c|}
\hline $\begin{array}{l}\text { BI\&A } \\
\text { phase }\end{array}$ & Key characteristics & $\begin{array}{c}\text { Gartner BI Platform Core } \\
\text { Capabilities }\end{array}$ & Gartner Hype Cycle \\
\hline$B I \& A 1.0$ & $\begin{array}{l}\text { Database management system- } \\
\text { based (DBMS) structured content } \\
\text { - } \quad \text { Relational DBMS (RDBMS) \& } \\
\text { data warehousing } \\
\text { - } \quad \text { Extraction, transformation } \\
\text { and loading (ETL) \& online } \\
\text { analytical processing (OLAP) } \\
\text { - Dashboards and scorecards } \\
\text { - Data mining and statistical } \\
\text { analysis }\end{array}$ & $\begin{array}{ll}\text { - } & \text { Ad hoc query \& search-based } \\
& \text { BI } \\
\text { - } & \text { Reporting, dashboards \& } \\
\text { - } & \text { Interecards } \\
\text { - } & \text { Predictive visualisation } \\
& \text { mining }\end{array}$ & $\begin{array}{l}\text { - } \text { Column-based DBMS } \\
\text { - In-memory DBMS } \\
\text { - } \text { Real-time decision } \\
\text { - } \text { Data mining workbenches }\end{array}$ \\
\hline BI\&A 2.0 & $\begin{array}{l}\text { Web-based unstructured content } \\
\text { - Opinion mining } \\
\text { - Question answering } \\
\text { - Web analytics and web } \\
\text { intelligence } \\
\text { - Social media analysis } \\
\text { - Social network analysis } \\
\text { - Spatial-temporal analysis }\end{array}$ & & $\begin{array}{l}\text { - Information semantic services } \\
\text { - Natural language question } \\
\text { - } \text { answering } \\
\text { - Content and text analysis }\end{array}$ \\
\hline BI\&A 3.0 & $\begin{array}{l}\text { Mobile and sensor-based content } \\
\text { - Location-aware analysis } \\
\text { - } \quad \text { Person-centered analysis } \\
\text { - } \quad \text { Context-relevant analysis } \\
\text { - } \quad \text { Mobile visualisation \& human- } \\
\quad \text { computer interaction (HCl) }\end{array}$ & & - Mobile Bl \\
\hline
\end{tabular}

Several of the BI platform core capabilities regarded as essential in Gartner's BI Platform Core Capabilities and BI Hype Cycle for Business Intelligence (Bitterer 2011) can already be found in leading commercial BI platforms. A number of these core capabilities are still under active development and are still in the hype phase as classified in the Gartner $\mathrm{BI}$ Hype Cycle analysis for emerging BI technologies (Sallam, Richardson, Hagerty \& Hostmann 2011). Sallam, Parenteau, Hostmann, Schlegel, Oestrich, Tapindhas \& Howson (2015) are of the view that BI\&A passed a tipping point as it shifted from IT-centric reporting-based platforms towards modern BI\&A platforms that will enable sharper analytics and greater agility. In the Hype Cycle for Business Intelligence and Analytics, 2015 (Schlegel 2015) a number of technologies are, however, still emerging, for example prescriptive analytics is still in the Innovation Trigger phase and can only be expected to mature in five to 10 years; predictive analytics is currently in the Peak of inflated expectations and can be expected to mature in two to five years; Big Data is currently in the Trough of disillusionment and can only be expect to reach maturity in five to 10 years.

According to Chen et al. (2012:1167-1168), unlike the key characteristics in the first generation BI\&A which are already available in the leading commercial BI platforms, the tools to support second generation BI\&A such as web analytics, social media analytics, social 
network analysis, spatial-temporal analysis still need to be integrated with existing BI\&A systems. With regard to the third generation BI\&A tools, Chen et al. (2012:1168-1182) is of the view that no integrated, commercial BI\&A systems are expected to be available in the near future.

While web-based BI\&A has attracted active research from academics and industry, research on aspects related to the third generation BI\&A is still emerging. It is expected to increase as a consequence of the number of mobile devices surpassing the number of laptops and personal computers in 2011. The emerging research areas based on the evolution of BI\&A include big data analytics, text analytics, web analytics, network analytics and mobile analytics (Chen et al. 2012:1168-1182). Learning analytics can be regarded as a special subset of big data analytics applicable to higher education institutions. West (2012:10) highlights the value of a data-driven approach to education and its contribution to informed decision making, but he also points to the need to balance student privacy with access to data for research purposes. See also Chapter 17 by Prinsloo.

The explosion of digital data in terms of volume, velocity and variety has led to the socalled big data phenomenon. According to McAfee \& Brynjolfsson (2012:62-68), managers can measure and know radically more because of big data, and this knowledge can be translated directly into improved decision making and performance. They point out that, although the technical challenges of using big data are very real, the managerial and cultural challenges are even greater. The implication for institutional researchers is therefore not only of a technical nature, but will also require an advocacy role to raise awareness among higher education decision-makers about these aspects. The importance of asking the right questions will also be critical. The impact will therefore be on all three of Terenzini's levels of intelligence. With regard to the implications for governance, Couldry \& Powell (2014:1) are of the opinion that "[w]e are living through a transformation of governance - both its mechanisms and reference points - which is likely to have profound implications ...". They maintain that emerging cultures of data collection deserve to be examined in a way that foregrounds the agency and reflexivity of individual actors and the variable ways in which power and participation are constructed and enacted. Couldry \& Powell (2014:4) are concerned that contemporary societies are characterised by the way that all largescale processes increasingly rely on total surveillance through the continuous gathering and analysis of data. In higher education, this has specific implications for learning analytics because of the power imbalance that exists between analysts, academics and students. A major concern is that what is measured does not constitute all aspects of learning and is therefore not complete. It may also not be objective (see Chapters 12 and 17).

The use of Big Data requires a radical shift in how institutional researchers think about research. Lazer, Pentland, Adamic, Aral, Barabási, Brewer, Christakis, Contractor, Fowler, Gutrmann, Jebara, King, Macy, Roy \& Van Alstyne (2009:721-723) point to the capacity to collect and analyse data of an unprecedented breadth and depth. The danger of big data on social media is highlighted by Oboler, Welsh \& Cruz (2012). They point out that social networking web sites generate vast quantities of data while the availability of modern tools makes it possible to analyse these data. This has significant implications for individuals and society because these data are largely controlled by businesses and governments. Oboler 
et al. are specifically concerned about the lack of transparency in the way these data are analysed, aggregated and used in predictions, while the individuals involved have a limited understanding of the potential negative effects this may have for them. Lyon (2014) points to important ethical implications in relation to big data based on the widely published case of Snowden's revelations about surveillance by the National Security Agency in the United States. boyd \& Crawford (2012:565) see a profound change at the levels of epistemology and ethics. They highlight the fact that big data reframes the key questions about the constitution of knowledge, the process of research, engagement with information and the nature and categorization of reality. According to them, we must ask difficult questions of big data's models of intelligibility before they crystallize into new orthodoxies. With the automation of particular kinds of research functions, the inbuilt flaws of this should be considered by the harvesters of big data. They highlight the potential change to the meaning of learning and the new possibilities and limitations that may come with these knowledge systems. They argue that we should in particular be concerned about what is missing, what is privileged in the analysis of big data and the fact that contextual factors are often excluded in clickstream data and analyses. They also highlight the importance of understanding the properties and limits of a data set, regardless of its size, and the importance of understanding the limitations and bias to which interpretation of the data, which is central to analysis, is subject to. This has implications for all three tiers of Terenzini's notion of institutional intelligence.

Ransbotham, Kiran \& Prentice (2015) highlight the fact that the translation of analytical insights into business actions remains difficult. While the analytical skills among managers are improving, the increasing sophistication of analysis is outpacing their increased abilities. This typically results in an analytics gap which creates a need for managers to become comfortable when applying analytic results they do not fully understand. Ransbotham et al. found that as the complexity of the analysis increases, the associated competitive advantage also increases. In terms of the complexity of analytics, they distinguish between descriptive analytics, predictive analytics and prescriptive analytics. Lastly, they also distinguish between production sophistication and consumption sophistication. Morgan \& Thayer (2016) highlight the fact that analytics can be used to improve student success and institutional efficiency. Thayer (2016) found that in spite of wide interest, only about a third of higher education institutions have an analytics strategy. She reported that the departments most frequently reported as being involved with analytics are Institutional Research, Finance, IT and Institutional Advancement. Although it is acknowledged widely that student outcomes need to improve, Morgan (2016) found that only a minority of higher education leaders regard learning analytics as a priority in their institution. She also reported that the focus is more on institutional analytics.

Lowendahl (2015) highlighted learning analytics and big data as important developments in higher education. Of the top ten strategic technologies impacting on higher education identified by Lowendahl, Thayer \& Morgan (2016a) the top two were Adaptive Learning and Predictive Analytics, which both impact on institutional researchers. Lowendahl, Thayer \& Morgan (2016b) identified student success, a key focus area for institutional researchers, as the top business trend in education. The Expert Group on Future Skills Needs (2014) also confirmed the demand for big data and analytical skills. Parenteau, Sallam, Howson, Tapinhas, Schlegel \& Oestrich (2016) highlight the shift from IT-led enterprise reporting to 
business-led self-service analytics. The role of institutional researchers as enablers of this shift cannot be underestimated. With more access to data and increasing analytical methods, it is evident that a gap is developing between the capacity of institutions to produce analytical results and the ability to apply the analysis effectively to relevant business issues. This clearly will impact significantly on Technical/Analytical intelligence and Issues Intelligence of IR practitioners.

The work of Giorgi, Lockwood \& Glynn (2015) on organisational culture can be used to understand organisational culture and the challenges described above, and can be used to address some of the concerns raised above concerning cultural aspects.

Many of the developments described above have started to find application in universities, and institutional researchers are beginning to deal with them. In some cases, institutional researchers are already doing excellent work in some of the areas. These aspects, however, still need to be developed considerably and integrated into the work of institutional researchers. It can be expected that these capabilities will require significant changes to the knowledge and skills of institutional researchers. In their advocacy and capacity as change agents, they will also have to play an important role in establishing and integrating these business intelligence and analytics capabilities into the management and decision-making of higher education institutions.

In order to achieve success with big data, it will be crucial to strike a balance between skills, talent and technologies (Dooley 2015:1-6). Dooley is concerned about the skills requirements in the area of big data. He highlights the exponential growth in data, in particular since 2011. The findings from a global Chief Information Officer (CIO) survey was that $72 \%$ of respondents ranked analytics and big data among their top technology initiatives, but Dooley is concerned about the complexity of the skills required in this area. He views big data as a team effort, but points out that the required skills will change and that numerous participants will be required. According to Moore (2015), a key success factor for implementing big data analytics is the organisation's ability to build, grow and sustain a multi-disciplinary team with the expertise needed to address identified business problems. Dooley also points to the critical role of flexibility because of the changing nature of technology.

From an institutional point of view, Prinsloo, Archer, Barnes, Chetty \& Van Zyl (2015:6-9) pose a number of theses to ensure that big or bigger data are better data. In their third thesis "The promise of Big Data offers a new world and requires a new skillset for analysts", Prinsloo, et al. (2015:7) specifically deals with some aspects of the skills and capabilities shift required from practitioners such as IR professionals while they are moving toward the use of big data. They argue that "researchers and stakeholders must now scope information needs to more exact questions" and note that "with more data comes more noise and also missing values". The 'new' institutional researcher must have skills to find or direct others to meaningful big data and make relevant connections. Programming skills in new languages, combined with multi-source data mining, statistical modelling and prediction are now required. While the development of algorithms will be part of this process, from an institutional and pedagogical perspective, an understanding of what drives student learning and success will remain key. Institutional researchers must balance the "what" provided by the patterns in data with the 
"why" which requires more in-depth investigation through traditional research approaches. Identifying correlations alone will therefore not be sufficient."

In their fifth thesis, Prinsloo et al. (2015:8-9) point to the importance of 'contextual intelligence' which refers to a greater understanding of the institution and how it functions. This is not confined to its operations, but includes the alignment of the strategic direction and the context of the organisation nationally and internationally. This argument is not only relevant in the big data debate but applies equally where institutions are realising the changes in internal and statutory reporting. This means that researchers and analysts will need to think very differently about the sourcing, extraction, manipulation and analysis of data. They argue the importance of identifying the opportunities available to uncover new and different patterns in data and also to employ new, different and more advanced analytics in this process. All this will require a different set of skills and will re-shape our understanding of 'institutional research' and 'analytics'.

The table below summarises a number of shifts from traditional institutional research skills to the demands of modern analytics.

Table 2: Shifts from traditional institutional research skills to the demands of modern analytics

\begin{tabular}{|c|c|c|}
\hline & More traditional institutional research & Modern analytics \\
\hline Data & $\begin{array}{l}\text { - } \\
\text { - } \text { Focarcity of data } \\
\text { - Generally historical, trend or snapshot } \\
\text { orientation }\end{array}$ & $\begin{array}{l}\text { - } \text { Big data } \\
\text { - } \text { - } \text { Gultiple data sources } \\
\text { - Generally trend and real-time data }\end{array}$ \\
\hline Skillset emphasis & $\begin{array}{l}\text { - Science of measurement including } \\
\text { instrument design and construct } \\
\text { measurement } \\
\text { - Data collection to ensure representativeness } \\
\text { and generalisations }\end{array}$ & $\begin{array}{l}\text { - } \text { Finding meaning in big data and making } \\
\text { - } \text { relevant connections } \\
\text { - } \quad \text { Programming skills } \\
\text { - } \quad \text { Statistical modelling } \\
\text { - } \text { Development of algorithms }\end{array}$ \\
\hline Approach & $\begin{array}{l}\text { - Multitude possible questions narrowed down } \\
\text { to more specific research questions }\end{array}$ & $\begin{array}{l}\text { - Big data not tailored to any questions, } \\
\text { narrowed down to information needs for } \\
\text { specific questions }\end{array}$ \\
\hline $\begin{array}{l}\text { Main } \\
\text { complexities }\end{array}$ & $\begin{array}{l}\text { - Limited granularity and ability to segment } \\
\text { due to small numbers } \\
\text { - } \text { Representativeness of sample and ability to } \\
\text { make inferences about the larger population }\end{array}$ & $\begin{array}{l}\text { - } \text { More data = more noise, difficulty to } \\
\text { determine which data is meaningful and } \\
\text { what the patterns are reflecting } \\
\text { - } \text { Missing values } \\
\text { - Data quality }\end{array}$ \\
\hline Driver & \multicolumn{2}{|c|}{ - Understanding what drives student learning and success } \\
\hline
\end{tabular}

Source: Prinsloo et al. (2015:7)

Faircloth, Alcantar \& Stage (2015) discussed issues and challenges encountered in using big data to study educational experiences and subsequent outcomes of specific cultural groups. They highlight the question of identity as crucial for analysis, pointing out the dangers of aggregating data out of context and cautioning institutional researchers about this. They indicate important implications for research, policy and practice and highlighted 
the need for a critical quantitative approach to large datasets in the research design and data collection, including the use of variables that are relevant to the research undertaken. Although the context of the study was American Indian and Alaska Native students in the USA, the issues it highlights can be regarded as important in other institutional research contexts as well. Shum (2012:1-12) provides useful insights into the impact and benefits of learning analytics at a micro-level (individual learners), meso-level (institution) and macrolevel (higher education system). He also provides useful recommendations to keep in mind when engaging with learning analytics. In particular, the aspects related to training are important to take note of for professional development initiatives.

Furthermore, several aspects of the information support cycle (McLaughlin \& Howard 2004:11-14) business intelligence and analytics lifecycle can be expected to be affected by the developments described above. Modelling, identifying concepts and the selection of measures will have to be expanded. The collecting, coding and sharing of data will be impacted significantly in terms of integration of data, in particular structured and semistructured, and possibly even unstructured, and data quality in a real-time or close to real-time environment. Data standards for newer data types, extraction, transformation and loading of unstructured data in addition to structured data, the storing and processing of large data will have a big impact. As highlighted above, the restructuring, analysis and integration of data will have to undergo important changes which will have a large impact on the professional development of institutional researchers. So too will the generalisation, delivery and reporting be impacted significantly by big data. Lastly, as we have pointed out above, influencing and decision-making will be impacted. Similarly, the three key roles of institutional researchers as custodian/supplier, broker/producer and manager/user will all be affected by big data.

The developments highlighted above will require ongoing professional development. In this regard, it can be expected that the role of networking between IR professionals and the need for professional development will increase. This will provide significant opportunities for subject associations such as the SAAIR, but will also put pressures on their resources.

\section{The way forward}

In this chapter we have mapped out the current and anticipated future needs of IR professionals against the organisational intelligence framework in order to determine gaps and potential gaps. We have also attempted to establish what it is that makes the professional development opportunities aimed at IR professionals effective. What remains to be done in this chapter is to consider the gaps in the professional development opportunities currently available to IR professionals. It is important to balance these expectations and tensions with the role and capacity of a professional association such as the SAAIR.

Huynh, Gibbons \& Vera (2009:63) argue that the "... role of institutional research professionals has changed. They have progressed from being data brokers who assemble and report data to knowledge managers who use experience and technical expertise to analyse data for insights they distribute across the institution". 
Leimer (2012) highlights the need to shift the perspective about who IR professionals are and what they do. She lists the following new roles for institutional researchers: knowledge creator, problem solver, communicator, connector, educator, tactician and change agent. In order to achieve this shift, institutional researchers will need to develop Terenzini's issues intelligence and contextual intelligence.

Chen et al. (2102:1183) highlight the importance of understanding business issues and framing the appropriate analytical solutions. This can therefore be linked directly to issues intelligence and contextual intelligence. They also refer to Davenport's emphasis on an organisational culture supporting informed fact-based decision-making (Davenport 2006). Furthermore, not only analytical skills will be required from IR practitioners, but also proper interaction and communication skills in order to contribute to meaningful and actionable knowledge.

In the previous section, the impact of new and expected developments in business intelligence and analytics were highlighted, pointing to new skillsets that will be required from institutional researchers. Pockets of capacity in some of these areas already exist among institutional researchers but these will have to be shared and expanded to ensure that institutional researchers keep up with these recent developments as they unfold in the near future and beyond. An increasing number of short learning programmes and training courses to address some of these requirements are becoming available, though often not in the traditional areas used by institutional researchers, but rather in the fields of data science. On the job training is not likely to be a major option, with the possible exception of some of the larger and more established IR offices. Mentoring should not only include mentoring of new institutional researchers by experienced professionals, but, especially in the more technology-orientated aspects, mentoring of older, more experienced institutional researchers by younger institutional researchers with relevant technological skill should be considered as well. This interaction could contribute to a better use of mentoring in institutional research. Collaboration across institutions, possibly via subject associations such as the SAAIR can play an important role in this regard. It is furthermore evident that the current professional development initiatives offered by subject associations such as the SAAIR will have to be expanded and enriched.

The Statement of Aspirational Practice for Institutional Research (Swing \& Ross 2016) can serve as starting point to expand the definition of decision makers in support of the emerging trends discussed in this chapter.

Whitchurch (2009) highlighted the need for the development of blended professionals in higher education. According to her, some institutional researchers will, together with some other professionals, move into the area between academic and administrative roles and blend their role to be in both worlds. In order to implement this successfully, support from higher education institutions will be required.

For institutional researchers to meet these new requirements, all role players will have to play their part in the professional development of IR practitioners to ensure that they have the knowledge and skills - in particular in issues intelligence and contextual intelligence - to be able to provide relevant and contextual information in support of evidence-based 
decision-making in their institutions. The acknowledgement, accommodation and support of the work of institutional researchers by higher education institutions will inform their future professional development.

\section{References}

Achieving the Dream. 2012. Building institutional capacity for datainformed decision making. Cutting Edge Series, No 3. Available: http:// www.achievingthedream.org/ CAMPUSSTRATEGIES/GUIDES/default.tp

boyd, D. \& Crawford, K. 2012. Critical questions for big data. Information, Communication \& Society, 15(2):662679. http://dx.doi.org/10.1080/136911 8X.2012.678878

Barnes, G. 2012. SAAIR evaluations 2009 to 2011. Report for the SAAIR Annual General Meeting, 3rd October 2012.

Bitterer, A. 2011. Hype Cycle for Business Intelligence. Research Note G00216086, 12 August 2011. Stamford: Gartner, Inc.

Breen, C.M., Jaganyi, J.J., Van Wilgen, B.W. \& Van Wyk, E. 2004. Research projects and capacity building. Water $S A, 30(4): 429$ 434. http://dx.doi.org/10.4314/wsa. v30i4.5094

Borden, V. \& Webber, K.L. 2015. Institutional and educational research in higher education: Common origins, divergent practices, in A.J. Calderon \& K.L. Webber (Eds.). Institutional Research and Planning in Higher Education: Global Contexts and Themes. New York: Routledge. 16-27.

Calderon, AJ. \& Mathies, C. 2013. Institutional Research in the Future: Challenges within Higher Education and the Need for Excellence in Professional Practice, in A.J. Calderon \& K.L Webber (eds.). New Directions for Institutional Research, 157:77-90. http://dx.doi. org/10.1002/ir.20040

Calderon, A.J. \& Webber, K.L. 2015. Institutional Research, planning and decision making in higher education today, in A.J. Calderon \& K.L. Webber (Eds.). Institutional Research and Planning in Higher Education: Global Contexts and Themes. New York: Routledge. 3-15.

Chan, S. 1993. Changing roles of institutional research in strategic management. Research in Higher Education, 34(5):533-
549. http://dx.doi.org/10.1007/ BF00991918

Chase, J.S. \& Tetlow, W.L. 1979. Experience is the child of thought, in R.G. Cope (ed.). New Directions for Institutional Research, 23:23-31. http://dx.doi.org/10.1007/ BF00991918

Chen, H., Chiang, R.H.L. \& Storey, V.C. 2012. Business intelligence and analytics: From big data to big impact. MIS Quarterly, 36(4):1165-1188.

Couldry, N. \& Powell, A. 2014. Big Data from the bottom up. Big Data \& Society, July-December 2014:1-5. http://dx.doi. org/10.1177/2053951714539277

Davenport, T.H. 2006. Competing on Analytics, Harvard Business Review, 84(1):98-107.

Dawson, L., Rogers, S. \& Webber, K. 2015. Alignment of IR works tasks to Terenzini's tiers of intelligence. Unpublished paper delivered at the 55th Forum of the Association for Institutional Research. 25-29 May 2015. http://dx.doi. org/10.13140/RG.2.1.1061/3925

Dawson, S. \& Siemens, G. 2014. Analytics to literacies: The development of a learning analytics framework for multiliteracies assessment. The International Review of Research in Open and Distributed Learning, September 2014:1-11. http:// dx.doi.org/10.19173/irrodl.v15i4.1878

Delaney, A.M. 1997. The role of institutional research in higher education: Enabling researchers to meet new challenges. Research in Higher Education, 38(1):1-16. http://dx.doi. org/10.1023/A:1024907527884

Dooley, B.J. 2015. Are you staffed for big data excellence? 15 July 2015. Available: http://rewrite.ca.com/us/articles/ management-cloud/are-you-staffes-forbig-data-excellence.html

Dressel, P.L. 1979. Institutional researchers: Created or educated? in Robert, G. Cope (ed.). New Directions for Institutional Research, 23:43-48. http://dx.doi. org/10.1002/ir.37019792307 
Edjlali, R. \& Beyer, M.A. 2016. Magic Quadrant for Data Warehouse and Data Management Solutions for Analytics, Research Note G00275472, 25 February 2016. Research Note G00294732, 15 January 2016. Stamford: Gartner, Inc.

Evans, L. 2009. Developing research capacity in the social sciences: a professionality based model. International Journal for Researcher Development, 1(2):123-149. http://dx.doi. org/10.1108/1759751X201100010

Expert Group on Future Skills Needed (EGFSN). 2014. Assessing the Demand for Big Data and Analytics Skills, 20132020. Dublin: Forfás.

Faircloth, S.C., Alcantar, C.M. \& Stage, F.K. 2015. Use of large-scale data sets to study educational pathways of American Indians and Alaska Native students, in R.S. Wells \& F.K. Stage (eds.). New Directions for Institutional Research, 163:5-24. http://dx.doi.org/10.1002/ ir. 20083

Fincher, C. 1978. Institutional Research as organizational intelligence. Research in Higher Education, 8(2):189-192. http:// dx.doi.org/10.1007/BF00992119

Gagliardi, J.S. \& Wellman, J. 2015. Meeting demands for improvements in public system institutional research: Assessing and improving the institutional research function in public university systems. National Association of System Heads (NASH). Available: www.nashonline.org/ institutional-research.

Giorgi, S., Lockwood, C. \& Glynn, M.A. 2015. The Many Faces of Culture: Making Sense of 30 Years of Research on Organization Studies. The Academy of Management Annals, 9(1):1-54. http:// dx.doi.org/10.1080/19416520.2015.10 07645

Hawson, C., Parenteau, J., Sallam, R.L., Oestreich, T.W. \& Schlegel, K. 2016. Critical Capabilities for Business Intelligence and Analytics Platforms, Research Note G00278437, 10 March 2016. Stamford: Gartner, Inc.

Howard, R.D. 2011. AIR history-governance, policies, and services - perspectives of past presidents 1965-2010, in M.A. Coughlin \& R. Howard (Eds.). The Association for Institutional Research: The first 50 years. Tallahassee: Association for Institutional Research (AIR), 53-110.

Huynh, B, Gibbons, M.F. \& Vera, F. 2009. Increasing demands and changing institutional roles: How technology can help, in C. Leimer (ed.). New Directions for Institutional Research, 143:59-71. http://dx.doi.org/10.1002/ir.305

Jones, M.L. 2001. Sustainable organizational capacity building: Is organizational learning a key? The International Journal of Human Resource Management, 12(1):91-98. http://dx.doi. org/10.1080/713769590

Klemenčič, M. \& Brennan, J. 2013. Institutional research in a European context: A forward look. In Special issue on the past, present and future of higher education research: Between scholarship and policy making. European Journal of Higher Education, 3(3):265-279.

Knight, W.E., Moore, M.E. \& Coperthwaite, C.A. 1997. Institutional research: Knowledge, skills and perceptions of effectiveness. Research in Higher Education, 38(4):419-433. http://dx.doi. org/10.1023/A:1024910409653

Lasher, W.F. 2011. The history of Institutional Research and its role in American Higher Education over the past 50 years, in M.A. Coughlin, M.A. \& R.D. Howard (Eds.). The Association for Institutional Research: The first 50 years. Tallahassee: Association for Institutional Research. 9-52.

Lazer, D., Pentland, A., Adamic, L., Aral, S., Barabási, A., Brewer, D., Christakis, N., Contractor, N., Fowler, J., Gutmann, M., Jebara, T., King, G., Macy, M., Roy, D., \& Van Alstyne, M. 2009. Life in the network: the coming age of computational social science. Science, 323(5915):721-723. PMid:19197046 PMCid:PMC2745217 http://dx.doi. org/10.1126/science.1167742

Leimer, C. 2012. Creating the new IR. Unpublished keynote address delivered at the North Carolina Association for Institutional Research (NCAIR) 2012 conference "The Art of Institutional Research". 12-14 March 2012, Winston-Salem.

Leimer, C. \& Terkla, D.G. 2009. Laying the Foundation: Institutional Research Office Organization, Staffing and Career 
Development, in C. Leimer (ed.). New Directions for Institutional Research, 143:43-58. http://dx.doi.org/10.1002/ ir.304

Lowendahl, J.-M. 2015. Hype Cycle for Education, 2015. Research Note G00277499, 8 July 2015. Stamford: Gartner, Inc.

Lowendahl, J.M., Thayer, T.-L.B. \& Morgan, G. 2016a. Top 10 Strategic Technologies Impacting Higher Education in 2016. Research Note G00294732, 15 January 2016, revised 19 April 2016. Stamford: Gartner, Inc.

Lowendahl, J.M., Thayer, T.-L.B. \& Morgan, G. 2016b. Top 10 Business trends Impacting Higher Education in 2016. Research Note G00294735, 15 January 2016. Stamford: Gartner, Inc.

Lyon, D. 2014. Surveillance, Snowden, and big data: Capacities, consequences, critique. Big Data \& Society, JulyDecember:1-13. http://dx.doi. org/10.1177/2053951714541861

McAfee, A. \& Brynjolfsson, E. 2012. Big data: The management revolution. Harvard Business Review, Oct 2012: 60-69. PMid:23074865

McKinney, E.B. \& Hinders, J.J. 1992. Science and Institutional Research: The links. Research in Higher Education, 33(1):19-29. http://dx.doi.org/10.1007/ BF00991969

McLaughlin, G.W. \& Howard, R.D. 2001. Theory, practice and ethics of institutional research, in R.D. Howard (ed.). Institutional research: Decision support in higher education. Tallahassee: Association for Institutional Research. 163-194.

McLaughlin, G.W. \& Howard, R.D. (eds.). 2004. People, processes and managing data (Second edition). Resources in Institutional Research Series No 15. Tallahassee: Association for Institutional Research.

Moore, S. 2015. How to prevent big data analytics failures. Gartner. Available: http://blogs.gartner.com/ smarterwithgartner/author/sumoore/

Morest, V.S. \& Jenkins, D. 2007. Institutional Research and the culture of evidence at Community colleges. Report No 1 in the Achieving the Dream Culture of
Evidence Series. New York: Community College Research Center, Teachers College, Columbia University.

Morgan, G. 2016. Assessing the State of Learning Analytics in Higher Education. Research Note G00295804, 27 April 2016. Stamford: Gartner, Inc.

Morgan, G. \& Thayer, T.-L.B. 2016. Three Important Ways the Analytics Landscape is Changing in Higher Education. Research Note G00300566, 3 March 2016. Stamford: Gartner, Inc.

Muffo, J.A. 1999. A comparison of findings from regional studies of institutional research offices, in J.F. Volkwein (ed.). What is Institutional Research all about? A critical and comprehensive assessment of the profession. New Directions for Institutional Research, 104:51-59. http:// dx.doi.org/10.1002/ir.10405

Muller, N., Langa, S. \& Dlamini, P. 2016. Institutional Research units in higher education institutions in Southern Africa: Organisational situation, staffing composition and trends, in J. Botha \& N. Muller (eds.). Institutional Research in South African Higher Education intersecting contexts and practices (in press). Stellenbosch: SUN MeDIA.

Oboler, A., Welsh, K. \& Cruz, L. 2012. The danger of big data: Social media as computational social science. First Monday, 17(2):1-15. Available: http:// firstmonday.org/ojs/index.php/fm/article/ view/3993/3269.

Parenteau, J., Chandler, N., Sallam, R.L., Laney, D. \& Duncan, A.D. 2014. Predicts 2015: Power Shift in Business Intelligence and Analytics Will Fuel Disruption. Research Note G00270932, 21 November 2014. Stamford: Gartner, Inc.

Parenteau, J., Sallam, R.L., Howson, C., Tapadinhas, J., Schlegel, K. \& Oestreich, T.W. 2016. Magic Quadrant for Business Intelligence and Analytical Platforms, Gartner Research Note G00275847, 4 February 2016. Stamford: Gartner, Inc.

Prinsloo, P., Archer, E., Barnes, G., Chetty, Y. \& Van Zyl, D. 2015. The International Review of Research in Open and Distributed Learning, February:1-11.

Ransbotham, S., Kiron, D. \& Prentice, P.K. 2015. Minding the analytics 
gap. MIT Sloan Management Review, Spring:63-68.

Ransbotham, S., Kiron, D. \& Prentice, P.K. 2016. Beyond the Hype: The Hard Work Behind Analytics Success. MIT Sloan Management Review, Spring:3-16.

Republic of South Africa. 2013. Higher Education and Training Information Policy. Government Gazette No 36973. Pretoria: Department of Higher Education and Training.

Romeu, J.L. 2011. Professional Organizations and the Learning of Statistics After College, in Proceedings of ASA Education Section, Vancouver CA, August 2011. Available: web.cortland.edu/romeu/ AsaPapJsmVanc10.pdf

Sallam, R.L., Richardson, J., Hagerty, J. \& Hostmann, B. 2011. BI Hype Cycle for Emerging BI Technologies. Stamford: Gartner, Inc.

Sallam, R.L., Parenteau, J., Hostmann, B., Schlegel, K., Oestreich, T.W., Tapadinhas, C. \& Howson, C. 2015. Critical Capabilities for Business Intelligence and Analytics Platforms, Research Note G00270381, 12 May 2015. Stamford: Gartner, Inc.

SARIMA. 2013. SARIMA Stakeholder Survey: Perceptions of SARIMA's service delivery and way forward in terms of capacity building and professionalization in Research Management. Feedback Report, 9 December 2013.

Schlegel, K. 2015. Hype Cycle for Business Intelligence and Analytics, 2015, Research Note G00278140, 4 August 2015. Stamford: Gartner, Inc.

Serban, A.M. \& Luan, J. 2002. Overview of Knowledge Management, in A.M. Serban \& J. Luan (eds.). New Directions for Institutional Research, 113:5-16. http:// dx.doi.org/10.1002/ir.34

Shaw, J. 2014. Why "Big data" is a big deal. Harvard Magazine, March-April:30-75.

Shum, S.B. 2012. Policy brief: Learning analytics. November 2012. Moscow: UNESCO Institute for Information Technologies in Education.

Slowey, M. \& Kozina, E. 2013. Practising what they preach? Academics' views on professional development for their teaching role, in E. Kozina \& C.OFarrell (eds.). Emerging issues in Higher Education III: From capacity building to sustainability. Dublin: All Ireland Society for Higher Education (AISHE). 55-67.

Swing, R.L. 2009. Institutional researchers as change agents, in C Leimer (ed.). New Directions for Institutional Research, 143:5-16. http://dx.doi.org/10.1002/ ir.301

Swing, R.L. \& Ross, L.H. 2016. The Statement of Aspirational Practice for Institutional Research. Tallahassee: Association for Institutional Research.

Terenzini, P.T. 1993. "On the nature of institutional research and the knowledge and skills it requires". Research in Higher Education, 34(1):1-10. http://dx.doi. org/10.1007/BF00991859

Terenzini, P.T. 2013. On the nature of institutional research revisited: Plus ça change ...? Research in Higher Education, 54(2):137-148. http://dx.doi. org/10.1007/s11162-012-9274-3

Thayer, T.-L.B. 2016. Assessing the State of Institutional Analysis in Higher Education. Research Note G00277044, 27 April 2016. Stamford: Gartner, Inc.

Volkwein, J.F., Liu, Y. \& Woodell, J. 2012. The structure and functions of Institutional Research offices, in Richard D. Howard, Gerald W. McLaughlin \& William E. Knight (eds.). The Handbook of Institutional Research. San Francisco: Jossey-Bass. 22-39.

Voorhees, R.A. \& Hinds, T. 2012. Out of the box and out of the office: Institutional Research for changing times, in Richard D. Howard, Gerald W. McLaughlin \& William E. Knight (eds.). The Handbook of Institutional Research. San Francisco: Jossey-Bass. 73-85.

West, D.M. 2012. Big data for education: Data mining, data analytics, and web dashboards. Governance Studies at Brookings, September 2012. Available: http://www.brookings.edu/ /media/ Research/Files/Papers/2012/9/04\%20 education $\% 20$ technology $\% 20$ west $/ 04 \% 20$ education $\% 20$ technology\%20west.pdf

Whitchurch, C. 2009. The rise of the "Blended professional" in Higher Education: A comparison between the United Kingdom, Australia and the United States. Higher Education, 58(3):407-418. http://dx.doi. org/10.1007/s10734-009-9202-4 